\title{
Monostephanostomum nolani sp. n. and M. krusei Reimer, 1983 (Digenea: Acanthocolpidae) from carangid fishes from coral reef waters off Australia
}

\author{
Rodney A. Bray ${ }^{1}$ and Thomas H. Cribb ${ }^{2}$ \\ ${ }^{1}$ Department of Zoology, Natural History Museum, Cromwell Road, London SW7 5BD, UK; \\ ${ }^{2}$ Centre for Marine Studies and Department of Microbiology and Parasitology, The University of Queensland, Brisbane, \\ Queensland 4072, Australia
}
Key words: Digenea, Acanthocolpidae, Monostephanostomum nolani, Monostephanostomum krusei, Carangoides plagiotaenia, Pseudocaranx dentex, Great Barrier Reef, Lizard Island, Ningaloo Reef, Western Australia

\begin{abstract}
Monostephanostomum nolani sp. n. is described from Carangoides plagiotaenia Bleeker, off Lizard Island, Great Barrier Reef, Queensland, Australia. It differs from all other species in the genus except M. manteri Kruse, 1979 in that the vitellarium reaches into the forebody. It differs from M. manteri in the ventral hiatus in the circum-oral spine row, the extent of the vitellarium in the forebody, where it is not confluent, its elongate pharynx and its smaller eggs. Monostephanostomum krusei Reimer, 1983 is redescribed from Pseudocaranx dentex (Bloch et Schneider) from Ningaloo Reef off Western Australia. It is considered similar to $M$. nolani, differing in the vitellarium being restricted to the hindbody, but sharing with M. nolani an unusual arrangement of small body-spines on the antero-ventral surface. It is also morphologically very similar to Monostephanostomum roytmani (Parukhin, 1974), which apparently lacks the diminutive antero-ventral body-spines. A key to eight recognized species in the genus is presented.
\end{abstract}

Monostephanostomum Kruse, 1979 was reviewed by Bray and Cribb (2002) who recognized four valid species, M. manteri Kruse, 1979, M. georgianum Bray et Cribb, 2002, M. gazzae (Shen, 1990) and M. mesospinosum (Madhavi, 1976). Saoud et al. (2002) recognized six species, M. manteri, M. krusei Reimer, 1983, M. yamagutii Ramadan, 1984, M. roytmani (Parukhin, 1974), M. mesospinosum and M. loossi (Pandey et Tewari, 1983). In this contribution we describe a new species and redescribe a species originally described in Monostephanostomum, but which Bray and Cribb (2002) considered a doubtful member of the genus.

\section{MATERIALS AND METHODS}

Digeneans collected from freshly killed fish were fixed by being pipetted into nearly boiling saline and immediately preserved in $10 \%$ buffered formalin or $70 \%$ ethanol. Wholemounts were stained with Mayer's paracarmine, cleared in beechwood creosote and mounted in Canada balsam. Measurements were made through a drawing tube on an Olympus BH-2 microscope, using a Digicad Plus digitising tablet and Carl Zeiss KS100 software adapted by Imaging Associates, and are quoted in micrometres, with the range and the mean in parentheses (Table 1). Circum-oral spines counts were made with the counting function of the digitiser.

The following abbreviations are used: BMNH, the British Museum (Natural History) Collection at the Natural History Museum, London, UK; QM, Queensland Museum Collection, Brisbane, Australia.

\section{RESULTS}

Family A c a n th o c o lpid a e Lühe, 1910

Genus Monostephanostomum Kruse, 1979

Monostephanostomum nolani sp. n. Figs. 1-3, 7-9

Description (based on 20 whole-mount preparations). Measurements and ratios of 13 specimens in Table 1 . Body elongate, narrow, widest in region of testes (Fig. 1). Tegument spinous; unarmed patch immediately posterior to oral sucker; individual worms may have blunt (Fig. 7) or sharp (Figs. 8-9) spines, but not both; spines vary in size; spines long in dorsal and lateral fields, on antero-ventral surface spines much smaller or difficult to distinguish, may be in distinct transverse rows of about 4 or 5 spines (Fig. 7), gradually increase in size posteriorly until at about mid-forebody ventral spines are of similar size to lateral spines, sharp spines reach about $90 \mu \mathrm{m}$ long, blunt ones reach about $35 \mu \mathrm{m}$, small ventral spines may be as small as $12 \mu \mathrm{m}$ long; spines smaller and becoming sparse in hindbody, reach to level of gonads or to posterior extremity. Eye-spot pigment granules scattered at level of mid-prepharynx. Oral sucker terminal, aperture anteriorly directed, distinctly wider than long. Circum-oral spines sharp or blunt, in single ring, with distinct ventral hiatus; spines decrease in size markedly towards ventral median line (Fig. 2). Ventral sucker oval, virtually equatorial. 


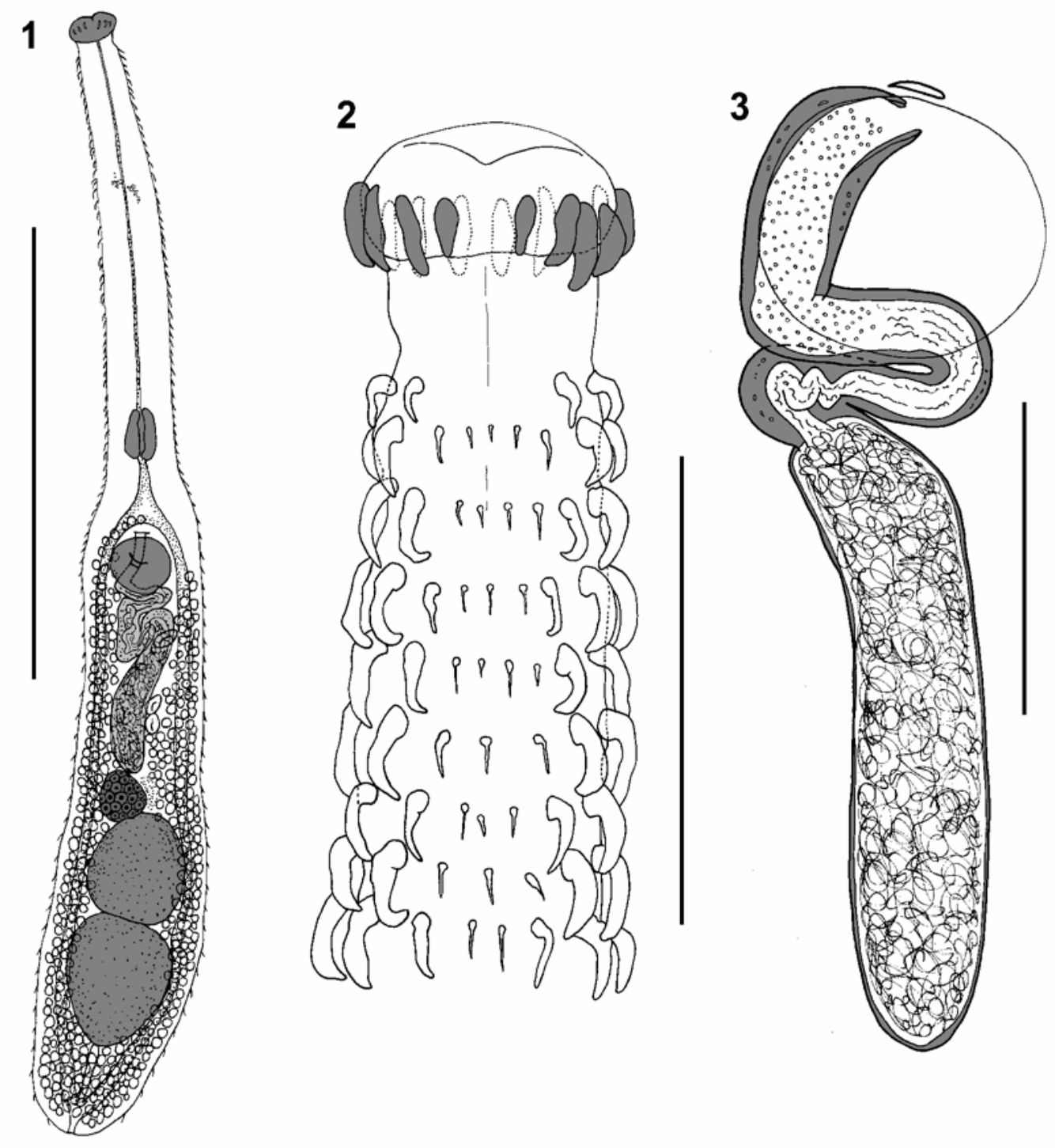

Figs. 1-3. Monostephanostomum nolani sp. n. Fig. 1. Ventral view of holotype. Fig. 2. Anterior extremity. Fig. 3. Cirrus-sac, ventral sucker in outline. Scale bars: Fig. $1=1 \mathrm{~mm}$; Figs. 2, 3=200 $\mu \mathrm{m}$.

Prepharynx very long. Pharynx elongate-oval. Oesophagus distinct. Intestinal bifurcation in posterior forebody. Caeca long, narrow, form uroproct.

Testes 2, oval, entire, tandem, contiguous. Posttesticular region short. Cirrus-sac elongate, coiled (Fig. 3), reaches well into hindbody, sometimes to ovary; anterior extremity dorsal to ventral sucker. Seminal vesicle saccular, oval, undivided, may be recurved anteriorly. Junction between pars prostatica and ejaculatory duct indistinct. In some specimens ejaculatory duct can be distinguished by weakly defined circles on wall of duct and in these cases pars prostatica can be taken as that part of male duct between this region and seminal receptacle. Ejaculatory duct with short, naked region distally. Genital atrium short, never reaching into hindbody. Genital pore median, slit-like, immediately anterior to ventral sucker.
Ovary oval, entire, antero-lateral to and contiguous with anterior testis. Mehlis' gland antero-dorsal to ovary. Laurer's canal not detected. Uterine seminal receptacle in proximal uterus. Uterus pre-ovarian, narrow, thick-walled throughout, with no clear transition to metraterm; small circles may be seen on wall of uterus/metraterm from midway between ovary and ventral sucker. Eggs large, thin-walled, tanned, operculate. Vitellarium follicular; fields reach slightly into forebody or occasionally to level of anterior part of ventral sucker; fields ventral and dorsal to caeca, confluent dorsally to posterior part of uterus, encroach slightly over dorsal surface of gonads, confluent dorsally and ventrally in post-testicular region.

Excretory pore terminal. Vesicle I-shaped, reaches to posterior edge of posterior testis. 
Table 1. Measurements in $\mu \mathrm{m}$, counts or ratios of Monostephanostomum spp.

\begin{tabular}{|c|c|c|}
\hline \multirow{4}{*}{$\begin{array}{c}\text { Measurement, count or ratio descriptor } \\
\text { Species } \\
\text { Host } \\
\mathrm{n}\end{array}$} & \multicolumn{2}{|c|}{ Measurement, count or ratio } \\
\hline & Monostephanostomum nolani sp. $\mathrm{n}$. & Monostephanostomum krusei \\
\hline & Carangoides plagiotaenia & Pseudocaranx dentex \\
\hline & 13 & 3 \\
\hline Overall dimensions & $2,072-2,963 \times 293-437(2,602 \times 343)$ & $2,504-2,708 \times 273-295(2,596 \times 287)$ \\
\hline Width as $\%$ of length & $10.3-17.0(13.3)$ & $10.6-11.5(11.1)$ \\
\hline Body-spines length: anterior mid-ventral & $12-13$ & $14-17$ \\
\hline Body-spines length: longest & $35-90$ & $39-41$ \\
\hline Oral sucker & $43-102 \times 81-134(76 \times 109)$ & $51-64 \times 115-126(58 \times 120)$ \\
\hline Oral sucker length as $\%$ of body-length & $2.00-4.6(3.0)$ & $2.0-2.5(2.2)$ \\
\hline Circum-oral spine counts & $17-20(17.9)$ & 17 \\
\hline Circum-oral spines: ventral & $20-50(31)$ & $27-31(28)$ \\
\hline Circum-oral spines: dorsal & $30-70(44)$ & $46-56(52)$ \\
\hline Ventral sucker (VS) & $121-215 \times 126-187(160 \times 159)$ & $115-138 \times 120-132(124 \times 127)$ \\
\hline VS length as $\%$ of body-length & $5.0-8.4(6.2)$ & $4.4-5.5(4.8)$ \\
\hline Sucker-length ratio & $1: 1.6-3.1(2.2)$ & $1: 1.8-2.7(2.2)$ \\
\hline Sucker-width ratio & $1: 1.2-1.9(1.5)$ & $1: 1.0-1.2(1.1)$ \\
\hline Forebody length & $724-1,302(1,075)$ & $898-1,199(1,048)$ \\
\hline Forebody as $\%$ of body-length & $32.4-48.6(41.3)$ & $35.9-44.3(40.3)$ \\
\hline Hindbody length & $935-1,605(1,366)$ & $1,389-1,468(1,423)$ \\
\hline Hindbody as $\%$ of body-length & $45.1-60.5(52.5)$ & $51.3-58.6(54.9)$ \\
\hline Prepharynx length & 389-921 (701) & $549-808(668)$ \\
\hline Prepharynx length as \% of body-length & $17.4-35.2(26.9)$ & $21.9-29.8(25.6)$ \\
\hline Pharynx & $101-253 \times 55-79(179 \times 68)$ & $152-168 \times 74-87(161 \times 80)$ \\
\hline Pharynx length as $\%$ of body-length & $4.7-9.9(6.9)$ & $6.1-6.3(6.2)$ \\
\hline Oesophagus length & $21-103(72)$ & $65-93(78)$ \\
\hline Intestinal bifurcation to ventral sucker & $0-101(53)$ & $59-93(75)$ \\
\hline Anterior testis & $203-310 \times 153-236(266 \times 207)$ & $190-212 \times 164-168(200 \times 167)$ \\
\hline Anterior testis as $\%$ of body-length & $9.2-12.5(10.3)$ & $7.0-8.5(7.7)$ \\
\hline Posterior testis & $271-386 \times 169-242(330 \times 208)$ & $229-237 \times 171-191(234 \times 178)$ \\
\hline Posterior testis as $\%$ of body-length & $11.1-15.0(12.8)$ & $8.8-9.4(9.0)$ \\
\hline Distance between testes (DBT) & 0 in 12 worms, 13 in 1 worm & 0 \\
\hline DBT as \% of body-length & 0 in 12 worms, 0.5 in 1 worm & 0 \\
\hline Post-testicular region (PTR) & $150-307(221)$ & $247-299(269)$ \\
\hline PTR as \% of body-length & $6.7-11.1(8.5)$ & $9.7-11.6(10.4)$ \\
\hline Cirrus-sac (CS) & $660-1,006 \times 64-105(857 \times 87)$ & $726-945 \times 70-75(857 \times 73)$ \\
\hline Cirrus-sac length as \% of body-length & $26.2-34.9(31.6)$ & $28.2-37.7(33.0)$ \\
\hline Distance from anterior end of CS to VS & Anterior end of CS always dorsal to VS & Anterior end of CS always dorsal to VS \\
\hline Distance from posterior end of CS to VS & $252-472(392)$ & $394-472(442)$ \\
\hline Above dimension as $\%$ of VS to Ovary & $83.3-100.1(93.9)$ & $67.1-79.4(74.2)$ \\
\hline Internal male duct length & $867-1,265$ (992) & $1,211-1,263(1,237)$ \\
\hline Seminal vesicle length (SV) & 299-487 (378) & $289-332(311)$ \\
\hline $\mathrm{SV}$ as $\%$ of internal male duct & $32.2-44.6(38.0)$ & $23.8-26.3(25.1)$ \\
\hline Pars prostatica length (PP) & $118-481(223)$ & $247-360(303)$ \\
\hline $\mathrm{PP}$ as $\%$ of internal male duct & $13.6-51.2(22.5)$ & $19.5-29.7(24.6)$ \\
\hline Ejaculatory duct length (EJ) & $142-507(391)$ & $562-684(623)$ \\
\hline $\mathrm{EJ}$ as $\%$ of internal male duct & $15.1-52.9(39.5)$ & $46.4-54.1(50.3)$ \\
\hline Genital atrium length & $20-29(23)$ & $22-28(25)$ \\
\hline Ovary & $85-142 \times 93-141(123 \times 111)$ & $92-104 \times 97-116(98 \times 106)$ \\
\hline Ovary length as $\%$ of body length & $4.1-5.4(4.7)$ & $3.6-4.0(3.8)$ \\
\hline Ovary to ventral sucker (Ov-VS) & $273-566(419)$ & $587-603(595)$ \\
\hline Ov-VS as $\%$ of body-length & $12.0-19.2(16.1)$ & $22.3-23.8(23.0)$ \\
\hline Eggs & $52-62 \times 30-40(56 \times 34)$ & $62-64 \times 39-44(63$ v 41) \\
\hline Anterior limit of vitellarium to VS & 0-95 (35) anterior & 94-161 (130) posterior \\
\hline
\end{tabular}


T y p e host: Carangoides plagiotaenia Bleeker, Carangidae; barcheek trevally.

$\mathrm{S}$ i t e : Intestine.

T y p e 1 o c a 1 i t y : Lizard Island, Queensland, Australia $\left(14^{\circ} 40^{\prime} \mathrm{S}, 145^{\circ} 28^{\prime} \mathrm{E}\right)$ (May, 2004 and June, 2005).

Prevale n c e : 3 of $3(100 \%)$.

Intensity: $2-3$.

De p o s ition of s p e c i m e n s : holotype QM G223043, paratypes QM G223044-223054, BMNH 2006.11.2.1-8.

E t y m o lo g y: This species is named for our colleague, Dr. Matt Nolan, in recognition of his expertise in collecting the hosts and his work on marine fish sanguinicolids.

\section{Monostephanostomum krusei Reimer, 1983}

Figs. 4-6, 10

Description (based on 3 whole-mount preparations). Measurements and ratios in Table 1. Body elongate, narrow, widest in region of testes (Fig. 4). Tegument spinous; unarmed patch immediately posterior to oral sucker; spines blunt, long in dorsal and lateral fields, on anterior ventral surface spines much smaller in distinct transverse rows of about 4 spines (Fig. 10), gradually increase in size posteriorly until at about mid-forebody ventral spines are of similar size to lateral spines; spines smaller in hindbody, becoming sparse, reach posterior extremity. Eye-spot pigment granules scattered at level of mid-prepharynx. Oral sucker terminal, distinctly wider than long. Circum-oral spines blunt, in single ring, with distinct ventral hiatus; spines decrease in size markedly towards ventral median line (Fig. 5). Ventral sucker oval, just pre-equatorial. Prepharynx very long. Pharynx elongate-oval. Oesophagus distinct. Intestinal bifurcation in posterior forebody. Caeca long, narrow, form uroproct.

Testes 2, oval, entire, tandem, contiguous, in one case slightly separated. Post-testicular region short. Cirrus-sac elongate, coiled (Fig. 6), reaches well into hindbody, but not to ovary; anterior extremity dorsal to ventral sucker or just anterior. Seminal vesicle saccular, oval, undivided. Pars prostatica relatively short, deeply convoluted. Ejaculatory duct long, complexly coiled, with 'cupolas' seen as distinct circles on wall of duct; short naked region distally. Genital atrium small. Genital pore median, slit-like, immediately anterior to ventral sucker.

Ovary oval, entire, antero-lateral to and contiguous with anterior testis. Mehlis' gland antero-dorsal to ovary. Laurer's canal opens dorsally to ovary. Uterine seminal receptacle in proximal uterus. Uterus preovarian. Eggs large, thin-walled, tanned, operculate. Vitellarium follicular; fields reach to about mid-level of cirrus-sac in hindbody, ventral and dorsal to caeca, confluent dorsally to posterior part of uterus, encroach over dorsal surface of gonads, confluent dorsally and ventrally in post-testicular region.
Excretory pore terminal. Vesicle I-shaped, reaches to posterior edge of posterior testis; no evidence of vesicle further anteriorly.

H o s t: Pseudocaranx dentex (Bloch et Schneider), Carangidae; white trevally.

$\mathrm{S}$ i t e : Intestine.

L o c a 1 i t y : Ningaloo, Western Australia $\left(22^{\circ} 42^{\prime} \mathrm{S}\right.$, $\left.113^{\circ} 40^{\prime} \mathrm{E}\right)($ April, 2000).

Prevalence : $1 / 1$.

Intensity: 3 .

Deposition of specimens: QM G223055223056, BMNH 2006.11.2.9.

\section{Remarks}

These two species are similar but are readily distinguishable by the anterior extent of the vitellarium.

On worms mounted dorso-ventrally it is inevitable that some lateral oral spines lie on top of each other and are difficult to distinguish. This may be more of a problem with Monostephanostomum, where there is a single row of spines, than with Stephanostomum Looss, 1899, where the two rows are staggered.

\section{Monostephanostomum nolani}

Utilizing the key in Bray and Cribb (2002) this worm, with the vitellarium reaching into the forebody, would be identified as Monostephanostomum manteri Kruse, 1979, known from species of the arripid perciform genus Arripis in the waters of southern and southwestern Australia (Kruse 1979, Bray and Cribb 2002). This key only included four species and it appears that there may well be more to be taken into consideration. Bray and Cribb (2002) suggested that M. krusei Reimer, 1983, from the carangid the bludger Carangoides gymnostethus (Cuvier) [syn. Caranx gymnostethoides (Bleeker)] from off Mozambique (Reimer 1983), is a lepocreadiid as it was apparently illustrated with an external seminal vesicle. In view of the similarity of this worm with $M$. nolani and our observations discussed below, we have reconsidered this view and think that it was originally correctly designated as a species of Monostephanostomum. Reimer (1983) compared his species with Stephanostomum roytmani Parukhin, 1974 from the carangid, the bigeye trevally Caranx sexfasciatus Quoy et Gaimard in the Gulf of Mannar, Indian Ocean (Parukhin 1974, 1976), which he considered likely to be a species of Monostephanostomum, although he did not form a new combination. These two parasites are very similar and should be compared with M. nolani. Saoud et al. (2002) discussed the distinction of the genera Monostephanostomum and Stephanostomum Looss, 1899, coming to similar conclusions as Bray and Cribb (2002), but added a further species to the genus in the form of M. loossi (Pandey et Tewari, 1984) from the scombrid Euthynnus sp. off Bombay, India (Pandey and Tewari 1984). They also formed the 

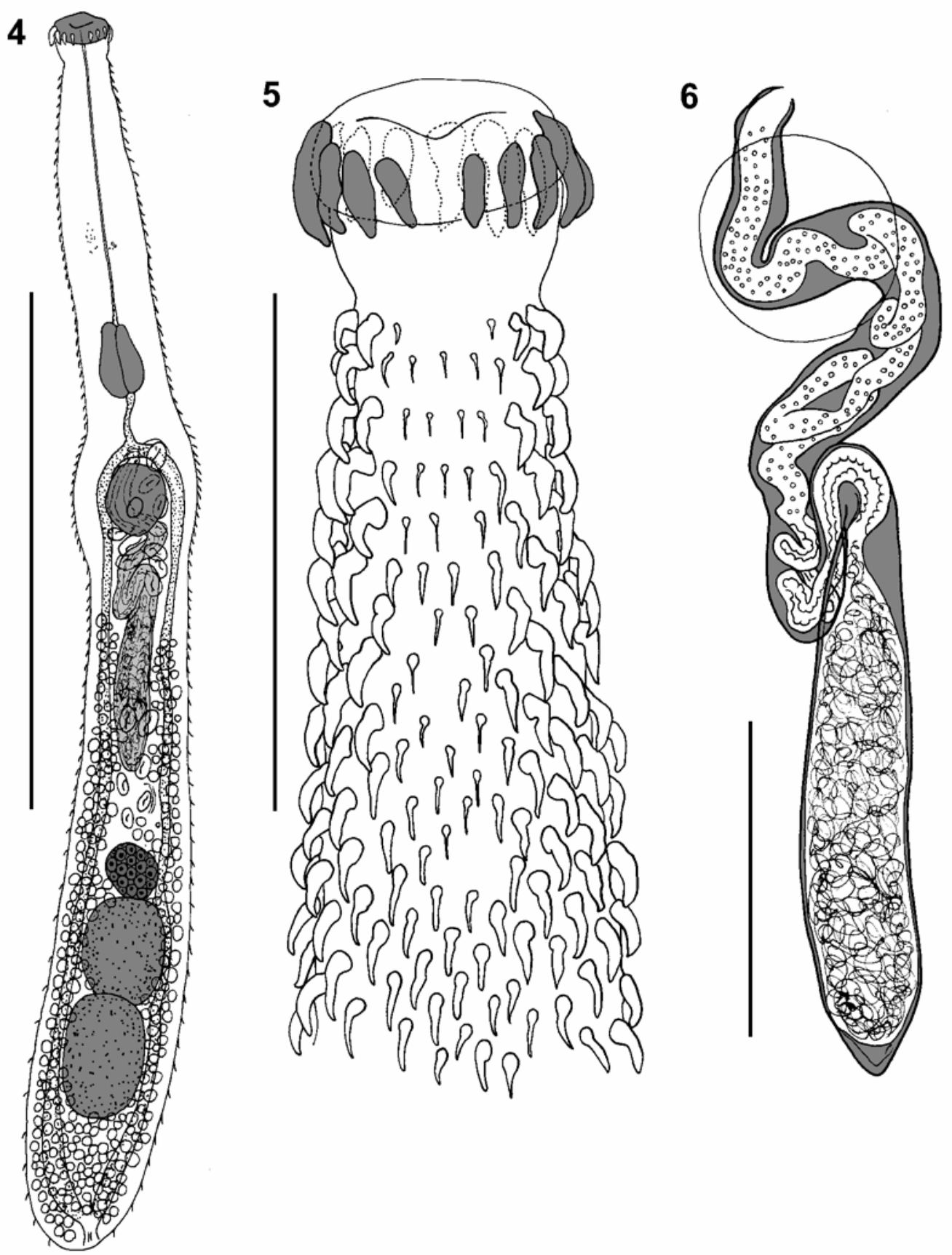

Figs. 4-6. Monostephanostomum krusei Reimer, 1983. Fig. 4. Ventral view of holotype. Fìg. 5. Anterior extremity. Fig. 6. Cirrus-sac, ventral sucker in outline. Scale bars: Fig. $4=1 \mathrm{~mm}$; Figs. 5, $6=200 \mu \mathrm{m}$.

combination $M$. roytmani. They recognized the validity of M. yamagutii Ramadan, 1984, in contrast to Bray and Cribb (2002), who thought it was probably a species of Stephanostomum. We have not changed our opinion on this species.

Monostephanostomum nolani can be distinguished from all species of the genus, apart from $M$. manteri by its vitelline extension into the forebody. It is distinguished from that species by the ventral hiatus in the circum-oral spine row, by its vitellarium, which only just reaches into the forebody, where it is not confluent, by the elongate pharynx and by its smaller eggs.

Monostephanostomum krusei and $M$. roytmani are similar in many features, including the ventral hiatus in the circum-oral spine row, the elongate pharynx, the long forebody and the carangid hosts, but in both of these species the vitellarium is restricted to the hindbody, reaching to about the mid-level of the cirrus-sac, 
and the cirrus-sac appears rather smaller. The unusual arrangement and size of the antero-ventral body spines has been described only in M. nolani. It is clear, however, that there is a group of similar forms from IndoPacific carangids.

The original illustration of Monostephanostomum loossi (see Pandey and Tewari 1984) shows that it is generally similar to $M$. krusei and M. roytmani, but it is said to have 32 circum-oral spines. It also differs from M. nolani in its vitelline distribution.

Monostephanostomum mesospinosum was described from the carangid the Malabar trevally Carangoides malabaricus (Bloch et Schneider) in the Bay of Bengal (Madhavi 1976). Although reported from the same genus of hosts as M. nolani it is easily distinguishable, being elongate, with the vitellarium restricted to the hindbody and interrupted at the level of the gonads.

As far as we are aware this is the first report of a digenean from Carangoides plagiotaenia.

\section{Monostephanostomum krusei}

We are identifying this form from Pseudocaranx dentex with the species described by Reimer (1983) as M. krusei from Carangoides gymnostethus, off Mozambique (see above). This species was originally described, from one adult and one juvenile, as having 18 circum-oral spines. The particular and striking arrangement of body-spines on the anterior mid-ventral region was not described by Reimer (1983), but the illustration shows the large body spines overlapping onto, but not reaching across, the ventral surface, as they do in our specimens. It is worthy of note that Reimer only illustrates the lateral spines in the other acanthocolpids described in this paper.

Our specimens should also be compared with $M$. roytmani (Parukhin, 1974) (Parukhin 1974). Reimer (1983) distinguished this species from M. krusei based on the circum-oral spine number (20) and the apparent lack of a uroproct in the illustration. At present, we agree that the species may be retained as distinct, as Parukhin (1974) illustrated large body spines across the antero-ventral surface of the worm and he stated that a typical feature of the worm is the presence of densely packed very large spines on the anterior part of the body. He described the caeca as reaching to the posterior end of the body, but does not mention a uroproct. These two characters, especially the body-spines, are used here to sustain the distinctness of M. krusei and $M$. roytmani. Due to the inconsistency of circum-oral spine counts, we do not think that the spine number is a sufficient distinguishing feature for these species.

Having added a further species to the genus and recognising two further likely species, we feel it is appropriate to update the key to the species.

\section{Key to species of Monostephanostomum}

1 Vitellarium reaches into forebody, occasionally to anterior margin of ventral sucker ................ 2

- Vitellarium restricted to hindbody ................. 3

2 Vitellarium confluent in forebody; pharynx oval, circum-oral spine row continuous; eggs 63-91 $\mu \mathrm{m}$ long ....................... M. manteri Kruse, 1979

- Vitellarium not confluent in forebody; pharynx elongate; circum-oral spine row with ventral hiatus; eggs 52-58 $\mu \mathrm{m}$ long .................... nolani sp. n.

3 Body elongate; gonads distinctly separated; vitelline fields interrupted at level of gonads ............... 4

- Body claviform; gonads contiguous or nearly so; vitelline fields continuous ....................... 6

4 Circum-oral spines in single uninterrupted row .... 5

- Circum-oral spines with short second row of spines dorsally ......... M. georgianum Bray et Cribb, 2002

5 Circum-oral spines 23; sucker ratio 1:2.0-2.5 ....... M. gazzae (Shen, 1990)

Circum-oral spines 18; sucker ratio 1:1.2-1.4. ...... .................. mesospinosum (Madhavi, 1976)

6 Circum-oral spines 32 M. loossi (Pandey et Tewari, 1984)

- Circum-oral spines 17-20 ....................... 7

7 Body-spines on antero-ventral surface small, in distinct transverse rows; uroproct present ....

M. krusei Reimer, 1983

- Body spines on anterior part of body very large; uroproct not reported

M. roytmani (Parukhin, 1974)

\section{Conclusions}

Monostephanostomum is characterized by a single row of circum-oral spines, a condition which contrasts with the two rows of Stephanostomum Looss, 1899 and Manteria Caballero, 1950 and the three to five rows of Stephanostomoides Mamaev et Oshmarin, 1966 (Bray 2005). Reimer (1983) also suggested that the relatively small number of spines, a distinct, narrow neck devoid of spines just posterior to the oral sucker, the uroproct and the ventral sucker in about the middle of the body constitute characters of the genus. All but the last remain valid after more recent studies by Bray and Cribb (2002) and Saoud et al. (2002) added the species $M$. mesospinosum, M. gazzae and $M$. georgianum. In all these species the forebody is relatively short. Most of the species of Monostephanostomum have 14-23 circum-oral spines; the exception is M. loossi with 32 . In view of this we have examined the list of Stephanostomum species in the appendix to Bray and Cribb (2003) to see whether there are any other likely candidates for a move to Monostephanostomum, but found that all the species within this range had already been 

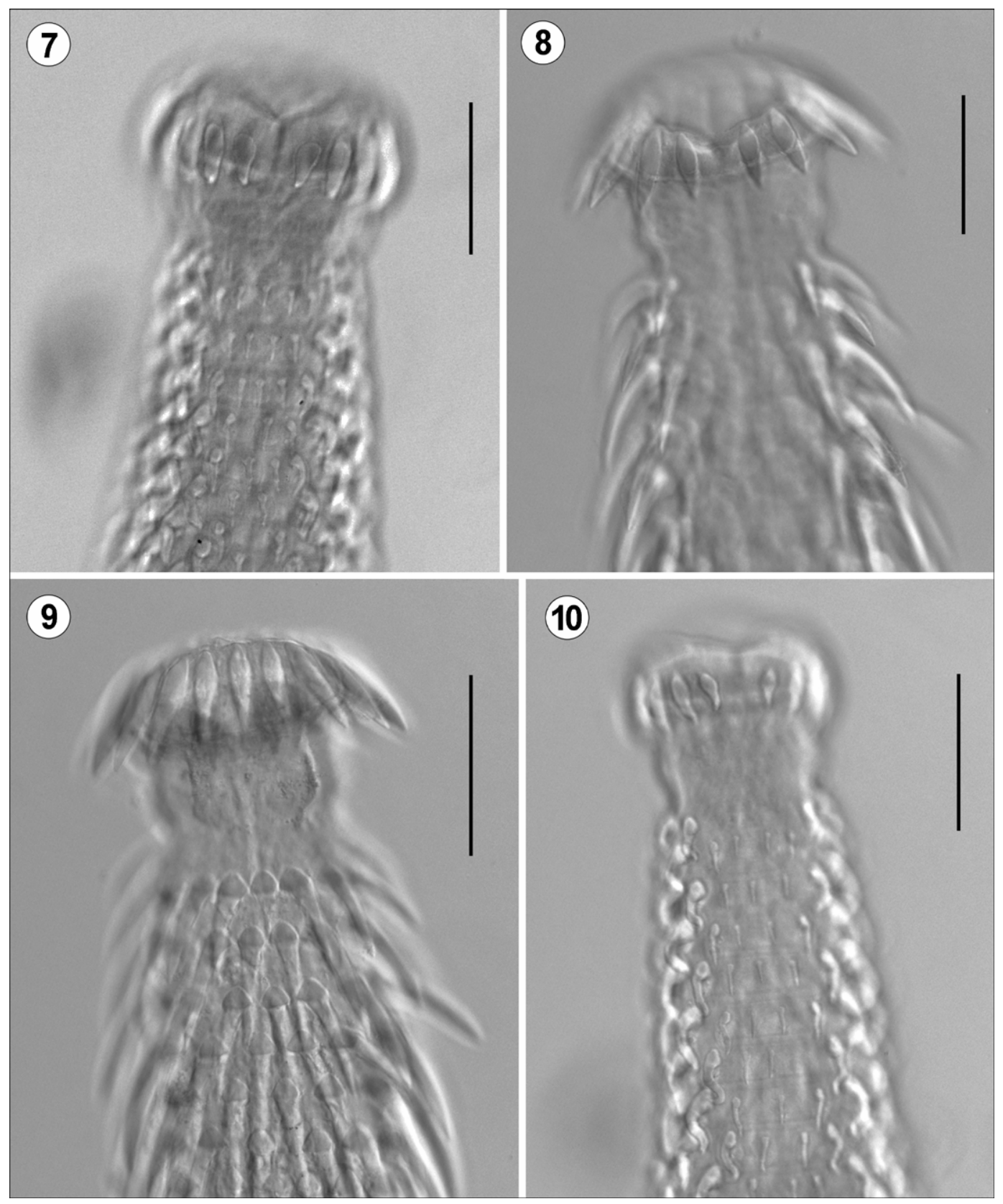

Figs. 7-9. Monostephanostomum nolani sp. n. Fig. 7. Anterior extremity, ventral view, showing usual arrangement of circumoral and body spines. Fig. 8. Anterior extremity, ventral view, showing unusual arrangement of large sharp spines. Fig. 9. Anterior extremity, dorsal view, showing unusual arrangement of large sharp spines. Fig. 10. Monostephanostomum krusei Reimer, 1983. Anterior extremity, ventral view, showing arrangement of circum-oral and body spines. Scale bars $=100 \mu \mathrm{m}$.

transferred. The only possible candidate is $S$. interruptum Sparks et Thatcher, 1958 with $22-23$ spines in a double dorsal row and a single ventral row. This species was considered to fall between the genera Stephanostomum and Monostephanostomum by Bray and Cribb (2002).

Our knowledge of the genus is still fragmentary, but a pattern of host-specificity is emerging. Although it was originally described from members of the genus Arripis (a genus and, indeed family, endemic to the waters off southern Australia and New Zealand), many of the species assigned to the genus since are parasites of members of the family Carangidae. Monostephanostomum appears restricted to the Indo-West Pacific Region.

Acknowledgements. We are grateful to Drs. Rob Adlard and Matt Nolan for assistance with the collection. This study has been supported by the Australian Research Council. Thanks are due to Drs. Boyko Georgiev and Andrea Waeschenbach for translation of Russian and German texts, respectively. David Gibson kindly read the manuscript. 


\section{REFERENCES}

BRAY R.A. 2005: Family Acanthocolpidae Lühe, 1906. In: A Jones, R.A. Bray and D.I. Gibson (Eds.), Keys to the Trematoda. Volume 2. CABI Publishing and the Natural History Museum, Wallingford, pp. 603-619.

BRAY R.A., CRIBB T.H. 2002: Monostephanostomum georgianum n. sp. (Digenea: Acanthocolpidae) from Arripis georgianus (Valenciennes) (Perciformes: Arripidae) off Kangaroo Island, South Australia, with comments on Monostephanostomum Kruse, 1979 and Stephanostomum Looss, 1899. Syst. Parasitol. 53: 61-68.

BRAY R.A., CRIBB T.H. 2003: Species of Stephanostomum Looss, 1899 (Digenea: Acanthocolpidae) from fishes of Australian and South Pacific waters, including five new species. Syst. Parasitol. 55: 159-197.

KRUSE G.O.W. 1979: Trematodes of marine fishes from South Australia. 6. Monostephanostomum manteri gen. et sp. n. (Acanthocolpidae). J. Parasitol. 65: 921-923.

MADHAVI R. 1976: Digenetic trematodes from marine fishes of Waltair Coast, Bay of Bengal. Family Acanthocolpidae. Riv. Parassitol. 37: 115-128.
PANDEY K.C., TEWARI S.K. 1984: On three new digenetic trematodes from marine fishes of Bombay coast, India. J. Zool. Soc. India 35: 60-65.

PARUKHIN A.M. 1974: Some new trematode species of the family Acanthocolpidae Luhe, 1909 from fishes of the Red Sea and Indian Ocean. Izv. Tikhook. Nauchn.-Issled. Inst. Ryb. Khoz. Okeanog. (TINRO) 88: 110-116. (In Russian.)

PARUKHIN A.M. 1976: [Parasitic worms of food fishes of the southern Seas]. Naukova Dumka, Kiev, 183 pp. (In Russian.)

REIMER L.W. 1983: Acanthocolpidae (Digenea) aus Fischen der Küste von Moçambique. Angew. Parasitol. 24: 134-146.

SAOUD M.F.A., NAHHAS F.M., AL KUWARI K.S.R., RAMADAN M.M. 2002: Helminth parasites of fishes from the Arabian Gulf: 10. Trematodes of the genus Stephanostomum Looss, 1899 (Digenea: Acanthocolpidae Lühe, 1901), with description of Stephanostomum qatarense $\mathrm{n}$. sp. and redescription of Stephanostomum triacanthi Madhavi, 1976. Riv. Parassitol. 29 (63): 87-103.

Accepted 30 November 2006 